\title{
АЛЬТЕРНАТИВНЫЕ МЕТОДЫ ХОЗЯЙСТВОВАНИЯ СТОКАМИ НА ПРИМЕРЕ ПРИДОМОВОЙ ОЧИСТНОЙ СТАНЩИИ В СЛАВЕ
}

\author{
А. МАЛЕЦКИ \\ Engineering Institute of Environment Zielona Gora 65 - 246 \\ Phone: 0480683254835 w. 612
}

Каждый человек вырабатывает определенное количество мусора в форме стоков. Существует проблема их уничтожения в большом объеме и отдельных домашних хозяйств. Неумножимые в основном запасы воды, а также связанные с этим все возрастающие расходы регуляции водньх отношений делают необходтмыпм их плантровочное хозяйствование.

Фактором влқиющим на сложность этой проблемы является одновременно возрастағопее количество отводимых стоков, влияютих на похужение запасов воды. При сегодняшнем количестве отводимых стоков некоторые резервуары указывают на тревогу загрязнения. Для обеспечения возможности постоянного побора воды улучпения ее качества применяют сознательные действия, стремящиеся $\mathrm{K}$ регулировке водных отношений. Особо трудньц для осуществления является проблема загрязнения поверхневых вод в области деревней и малтенькх поселков. В этой ситуации надо применить дешевые, нетрудные в обслуживании устройства, не требующие особого оборудования. Применение такого типа устройств обусловлено многими факторами. Особое значение кмеет проблема нагрузки стоками очистных устройств, а также такие элементы как: параметры загрязнения, местные почвовые условия, состояние подпочвенньх и поверхневых вод, величина предусматриваемого устройства, возможности эксплуатации, оборудования, велицина имения, итд. Обще говоря, решағот условия среды и экономии. В последние годы в Польше появилось много решений небольших придомовых очисток, строенных на основе подмокших экосистем, т.н. «ветландов». Это есть натуральные очнстки испопьзуюшие растения болотньг экосистем для задержки и разложения загрязнений супествующих в водах и стоках. В польской литературе приняли прогноз, что 30 - $80 \%$ наших деревней будут оборудованы устройствами этого типа. Кажется, что в искусственных системах, использующих болотные экосистемы, процесс очистки происходит продуктивнее чем в натурапьных системах. Сегодняшнее состояние знаний в специалистических обработках национальных и зарубежных (свьше 100 позиций), в области защиты вод этого типа устройствами, составляет условия стройки корневьх очистных станций, адекватньх размеру проблемы. Принимая во внимание способ переплыва стоков доминирующие биологические процессы, выделяғот два типа очистных станций, стимулируюоиих работу болотных экосистем:

- системы с поверхневьм протоком (FWS - Free Water Surface), образованные на стоковые пруды,

- системы с подповерхневьм протоком стоков через грунт (VSB Vegetated Submerget Bed), образованные на подтопленные грунтовые фильтры.

Системы FWS характеризуют самые низкие цены установки и простая гидравлика. Однако преимущество систем VSB состоит в возможности устранения лишних запахов, поменьше единичной поверхности по $1 \mathrm{MR}$ (Жилец 
Эквивалентный) а также большой устойчнвости на низкие температуры. В аналогичной лттературе VSB подразделяется на два типа:

- Max Planck Institute - MPI, где выполнение залежи состоит из крупнозернистого материала, чаще всего гравий и песок с подходяпей грануляцией,

- a также тип RZM (Root Zone Method), в которых как вьшолнение применяется мелкие пески или почва.

Существующие в стране очистные станции типа RZM указуют на лучшую элиминацию биогенных соединений, благодаря более эффективной сорбцип этих ионов. Но тип MPI указует более хорошую редукцию эмульсии и лучшую минерализацию органичных субстанщий благодаря более быстрой дифузик кислорода. Рисунки 1, 2, 3 представляют схемы этих устройств.

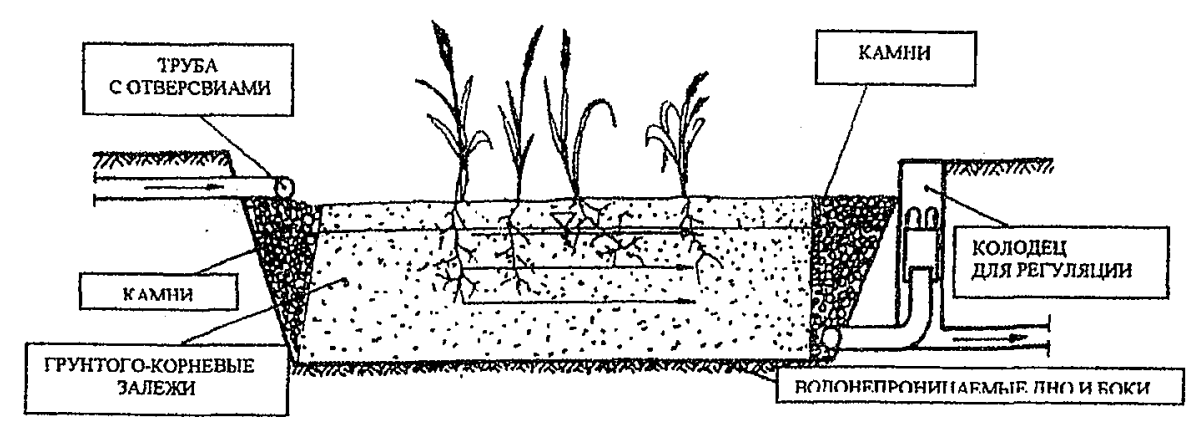

Рис. 1.1. Схема грунтово-растенных фильтров с горизонтальным протоком.

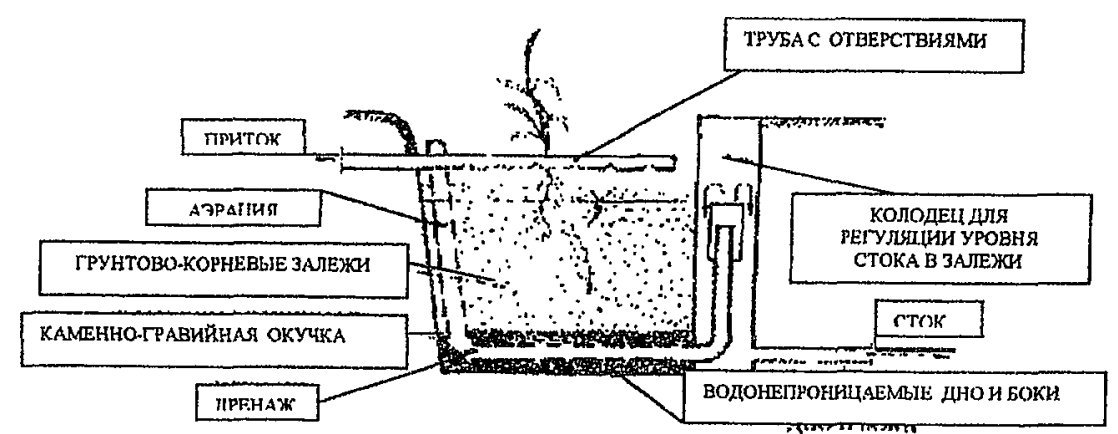

Рис. 1.2. Схема грунтово-растенных фильтров с вертикальным протоком.

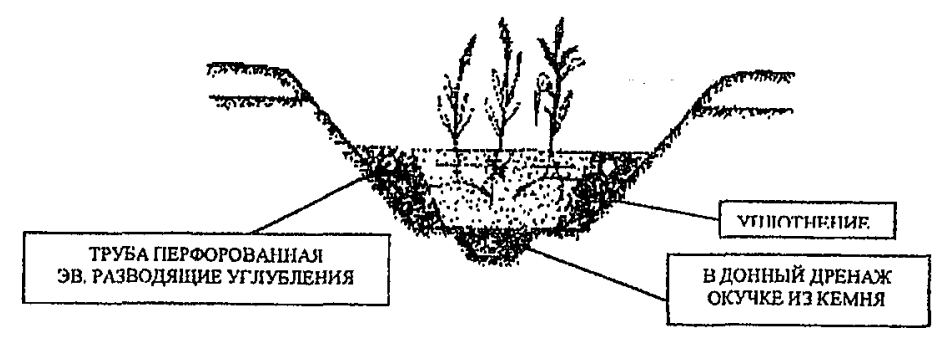

Рис. 1.3. Схема трунтово-растенных фильтров с вертикально-горизонтальным протоком. 


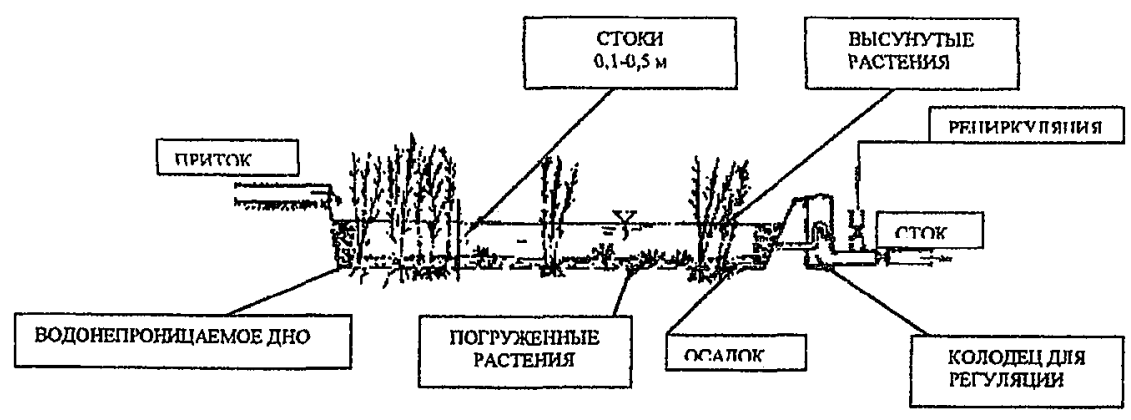

Рис.2.1. Принципиальная схема резервуаров с водными укоренившимися растениямк.

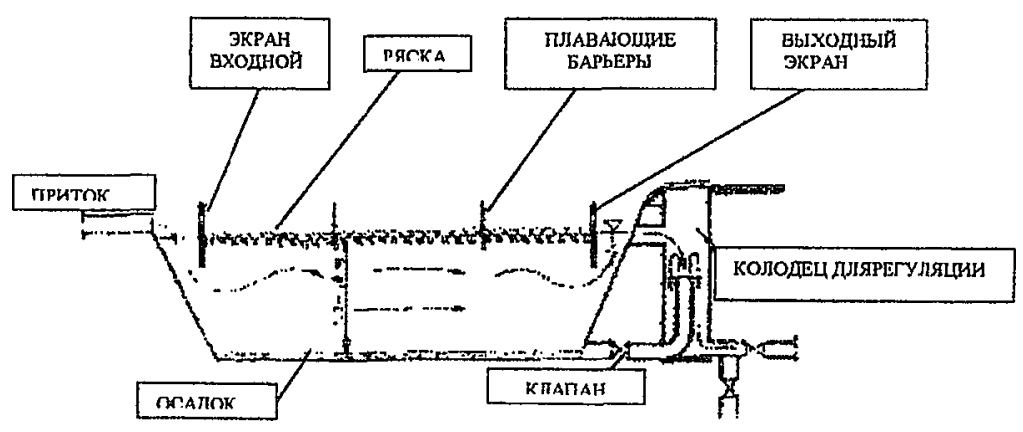

Рис.2.2. Принципиальная схема резервуара с плавающими растениями.

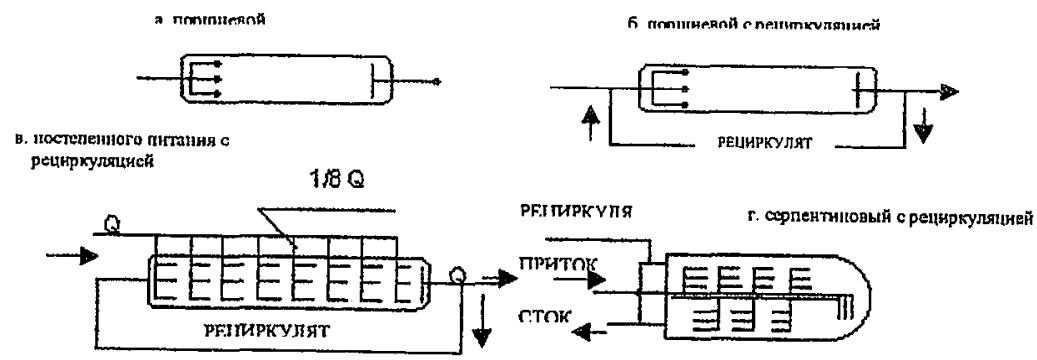

Рис.2.3. Схема протока через резервуар с водными растениями.

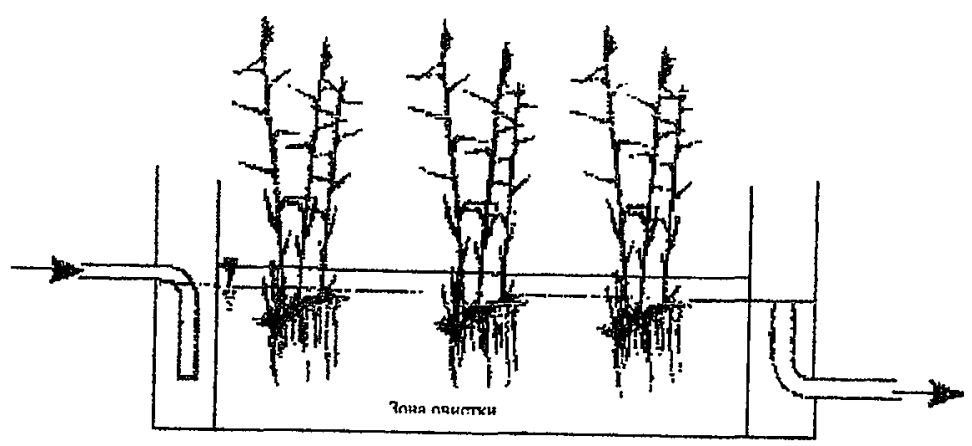

Pис.3.1. Схема грунтового фильтра типа VSB. 


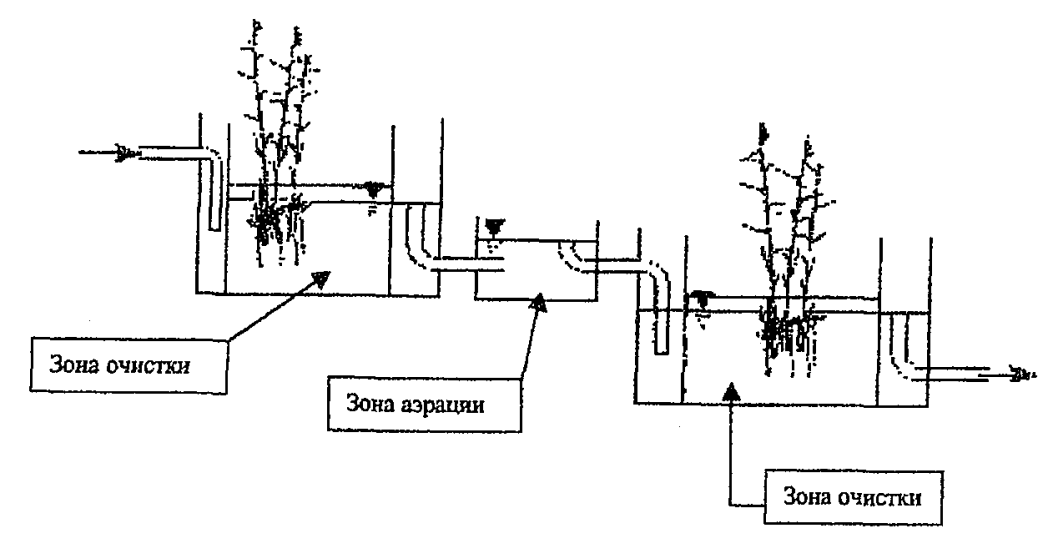

Рис.3.2. Рядовая схема фильтров типа RZM

При рассматривании решения стройки, растирения или перестройки очистной станщии стоков надо принимать во внимание эфект очистки т.е. коэфициент полезного действия, редукцию ВZT, эмульсии, нагрузку поверхности загрязнениями, гидравлическую нагрузку поверхности, гидравлическую нагрузку поперечного разреза протокового, время ретенции стоков хтд. В этой группе методов очистки стоков находятся такие устройства: грунтовые фильтры без растений, дренажи разисточающие, орошенные поля, поля использованные сельскохозяйственно, рыбные пруды, пруды стабилизационные, пруды аэрационизированные итд. Номенклатура, касающаяся растений очистной станции стоков не является еше в нашей литературе однородной. Hапример prof. Kowalik применяет общее название «гидроботаническая очистная станция» и подразделяет еe на четыре групшы, prof. Osmolska - Mróz называет их корневьми устройствами. Требования и тщательные технические решения находятся в упомянутой литературе.

В Славе господин Paul Fiedler, повиноватьй Аркадия разработал простой и очень оригинальный полезный для распространения метод очистки бытовых стоков, в котором используя как вьше растения болотвые, а также гетеротрофы, получает высокий уровень очистки стоков. Улучптил систему очистки в том направлении, чтобы применяемый материал выполняющий показывал свойства сорбции свойственные залежам RZM, а также делал возможным аэрациюо стоков до сих пор полученньх в залежах MPI.Реализация этой идеи продолжалась с 1992 года по 1994 год и дальше подвергает перестройке. Проэкт опкрается на осадковые технические каскады, очень тщательную нитрификацию в основной одистке. Следующие стоки передаются по методу гравитации в гидробиологический пруд, из которого кх периодицески разисточают. Тщательная основная очистка в этой модели является основой следующих процессов. Технология эта является комплексной циклицески работающей системой. Начинается с осветления стоков и последующей очистки на семи уровнях. Рис. 4 представляет схему придомовой счистной станции Paula Fiedlera в Славе. 


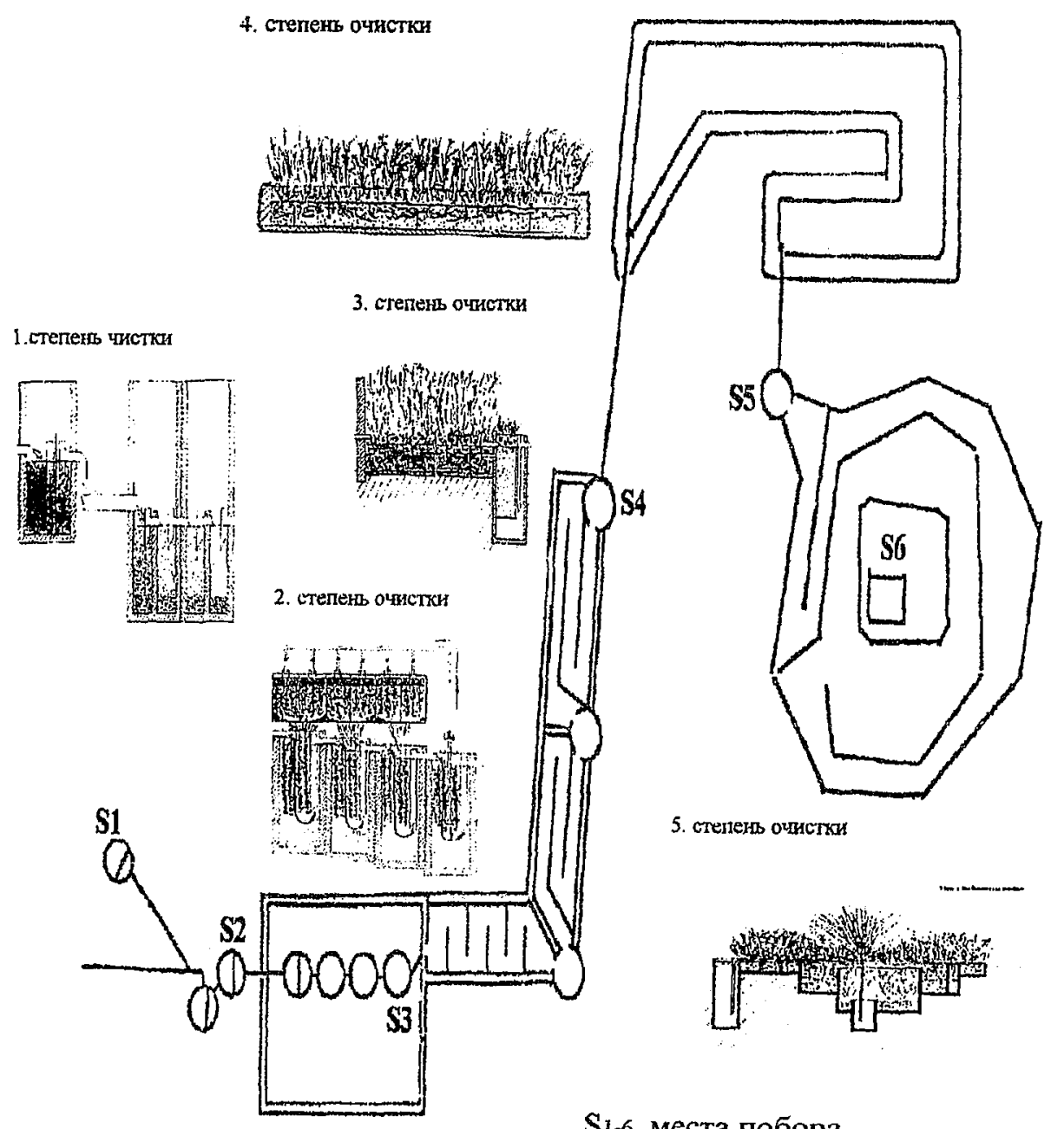

Si-6 места побора

Рис. 4. Схема придомовой очистной станции Paula Fiedlera в Славе.

Следующие цифры и относящие схемы показьвают следуютие степени оपारстки:

1. Многокамерный протоковый отстойник,

2. Каскадное биологическое залеже,

3. Поле с болотными растениями - третий каскад,

4. Шлюз с болотными растениями - третий каскад,

5. Пруд с багенными растениями - третий каскад,

6. Периодическое разисточание,

7. Грунтовьий фильтр.

Процесс очистки начинается из гравитационного стока из собирательного резервуара (1) - первый каскад до четырехкамерного отстойкика (2), с биологической диафрагмой - второй каскад. Биологически отппенные стоки допљьвают следующе к первому полю с растениями (3), а следующие - к второму полю (4). Сток стоков в пункте измерения S4 имеет параметры питьевой воды и дальше отводят ее qерез второе поле с болотньщии растениями к пруду (5) третий каскад. В первом каскаде происходит осаждение эмульсии - это механическая очистка - здесь наступает осветление стоков. Восстающий здесь «верхний застывший слой» периодически собранный и испотребляемый в 
процессе готовления компоста из стоков. Поднимавшиеся безлитниновые осадки из остальной части осадочного резервуара являются использованными в процессе получания биогаза. Необходимо, чтобы в следуюпкй каскад поплыли стоки без органичных частей твердой фазы и плавающих эмульсий. Это творит лучшие условия развития специализированньг микроорганизмов биологической диафрагмы. Второй каскад, при чем залеже - это вывод вверх осадка, развиваются здесь культуры микроорганизмов, специально за которыми ухаживали. Являются ими теплолюбивые нитрификационные бактерии. Здесь осаждается большинство загрязнения. Необходимые условия роста и развития неорганизованным сотворяет энергия полученная из солнечной батареи с применением закрытого цикла воды. Здесь появляются условия горного ручья. Каскад этот изолирован, а термичныте условия и вынужденный цикл воды, управляемые автоматически. Это противодействует бескислородной зоне, что на этом уровне является полезньм. Противодействует также кольмахированию залежи. В третьем каскаде неитрализуются биогенные химические вещества. Составляют ее четыре уровня болотньх растений, где гравий с ответствующей грануляцией является базой. Все составляет биологический путь с 30 см скатом, который завершаеться каскаднып прудом. Направпение стока регулировано так чтобы все пространство поля было наполнено стоками, а их уровень поддерживан несколько выте корневой зоны. Первое поле имеет глубину 30 см и наполнено камнями калибра $20-70$ мм. Здесь растет Miscanthus sinensis в восьми сортах, в три штуки на $1 \mathrm{~m}^{2}(3 / \mathrm{M})$. Осенью получаем около 30 тонн/гектар биомассы, которую после подсушения брикетировки хозяин сжегает в придомовой котельной. Задерживание стоков происходит в течение около месяца. На втором поле растет тростник, (pelka - brak odpowiednika w literaturze), (oczesek - brak odpowiednika), камыш, осока. В этой части стоки задерживаются около двух недель. Пруд окисляется с помощью упомянутой альтернативной энергии. Его средняя глубина около $2,5 \mathrm{~m}$, максимальная - около 4 м. Как видно на рисунке - это составное устройство. Также и здесь вода доплывает перез лабиринтный путь с водными растениями. $\mathrm{B}$ пруду находятся условия для развития многих родов беспозвономных т. н. фильтраторов из рода Daphnia, Cyklopus, что нарочно ограничивает развитие фитопланктона. Перед последним этапом третьего каскада наступает периодическое раздаждевывание воды из пруда. Вода протекает через земной фильтр с толшиной около 8 м и тогда попадает в грунтовые воды, которые выступают на этом уровне. По этому способу завершается мальый цикл воды. Весь путь стоков является 25 километровым ручьем, составленным из бассейнов оплавыванных стоками и воздухом, наполнекиых залежами из шляка, гравия, камня, болотных растений. Регуляция температуры стоков и воздуха позволяет на оптимальное развитие микроорганизмов психрофильных, мезофильных, нитрификационных. Весь объект находитсл на двух арах и расчислен на $60 \mathrm{RM}$. Основой вычисления являются следующие основные идеи:

- использование воды на 1 лицо в сутки - ок. 100 л.

- Количество кала на 1 лицо в сутки $500 \mathrm{r}=100 \Gamma$ sm=75 г ОТМ= C/N $1: 8$

- Количество мочи на 1 лицо в сутки 1500 г C/N 1:1

- Колидество загрязнений для неитрализации при 100 л стоков на 1 лицо в сутки,

- BZT $_{5} 60$, CZT 90г, 15г N, 3г P

Эфекты работы и в следуюших годах деятельности очистной станщии исследовал WIOŚ в Зеленой Гуре. На схеме очистной станцит назначено место для отбора пробок в пести измерительньх пунктах, где определяются 43 
показателя. Пробки со стоками берутся два раза в год т.е. в начале весны и осенью. В этой статье представлены средние величины важнейпих показателей из осени 1997 года. На основе данных WIOŚ в Зеленой Гуре. Стоки ймели слабый растительный запах, неопределенную реакцию, низкую концентрацию органических загрязнений, хлоридов, сульфидов, азота, фосфатов, железа, тяжелых металлов, растворимых веществ и общей эмульсии. Физико химический состав анализированньг стоков соответствует допустимьм величинам показателей загрязнений в стоках, которые переходят в воды и подву. Коэфищиент полезного действия очистки превышает $95 \%$. Система имеет хоропую редукцию органических загрязнений, эмульсии и биогенных элементов. Очистная станция находится на площади 2 аров, что в предлагаемьтх типах корневых очистных станщий требует больших площадей, средне около $5 \mathrm{M}^{2} / \mathrm{MR}$. Рекомендованная очистная станция функционирует также и зимой, когда общее мнение о работе установок этого типа является менее оптимистическим. Объект не требует конвенционального источника питания. Вторичный цикл стоков во втором каскаде, мешание воды в пруду, ее разрашание имеет альтернативный источник питания. Подчеркиваюот, что проэкт устройства опирается на циклический, а не линейный цикл стоков. Шламы осаждағотся и не принимают участия в цикле стоков. Это следующее новое по отношению к существующим типам корневых очистных станций. Цикл стоков обозначает, что стоки после очистки и получения показателей питьевой воды питают подземные воды, откуда берут их для вторичного использования и имеко они лучшие показатели чем вода из крана.

Кроме того, конструкция сделанная из натуральньгх материалов, часто из отбросов, эстетически вкомпонированна в окружающие посессии. Надо также сказать, что имеет больщой общественный оттенок, а автор проэкта, исполнитель и владелец в одном лище получил в проплом году премию воеводы Зеленой Гуры, министр OSZNL вручил ему медаль Заслуги для окружаюощей среды и хозяйствования водами. Высокая эфективность очистной станции возможна благодаря точному подбору сортов гидрофилевой растительности, которая по своему и в определенной очереди побирает от стоков биогенныте вегества. Самые важные показатели качества очищенных стоков соответствуют поверхневым водам с первым классом чистоты и исполняют требования для питьевой воды. Презентированная очистная станция - это следующий метод очень эфективной очистки стоков и их рационального использования в отечественных условиях, надо вести дальше исследования а также распространять объекты, исполняющие желания. Эта статья не исчерпьвает всего объема темы. Это новая технологическая проблема в нашей стране. Появляется много замечанхй, касающихся самых важных дел. Целенаправленным является ведение реестра существующих очистных станций этого типа а также систематически собирать данные, касающиеся их функщионирования и эфектов. Собранная информация должна служить для обработки точностей существующих проэктов, исправления эксплуатапии а также для урегулирования в области легислатуры. 
Таблица 1

Параметры очистительной станции для шести пунктов измерения в $\mathrm{r}$. WIOŚ Зеленая Гура

\begin{tabular}{|c|c|c|c|c|c|c|c|c|}
\hline \multirow{2}{*}{\multicolumn{2}{|c|}{$\begin{array}{c}1997 \\
\text { Показатели }\end{array}$}} & \multirow{3}{*}{$\begin{array}{c}\begin{array}{c}\text { Cотоки } \\
\text { cypoвble }\end{array} \\
\text { S1 }\end{array}$} & \multicolumn{5}{|c|}{ Редукция загрязнений } & \multirow{3}{*}{$\begin{array}{c}\begin{array}{c}\text { Kracc } \\
\text { uucmombt }\end{array} \\
-\end{array}$} \\
\hline & & & \multirow{2}{*}{\begin{tabular}{|c|}
$\begin{array}{c}\text { nocke mex } \\
\text { ouncmxu }\end{array}$ \\
$\mathrm{S} 2$
\end{tabular}} & \multirow{2}{*}{\begin{tabular}{|c}
$\begin{array}{c}\text { nocre биол. } \\
\text { ouнстики }\end{array}$ \\
$\mathrm{S} 3$
\end{tabular}} & \multirow{2}{*}{$\begin{array}{c}\begin{array}{c}\text { noche I } \\
\text { norsa }\end{array} \\
\mathrm{S} 4\end{array}$} & \multirow{2}{*}{$\begin{array}{c}\begin{array}{c}\text { nocue } I I \\
\text { nond }\end{array} \\
\text { S5 }\end{array}$} & \multirow{2}{*}{\begin{tabular}{|c|}
$\begin{array}{c}\text { Boda } \\
\text { npydy }\end{array}$ \\
S6
\end{tabular}} & \\
\hline Место побора & - & & & & & & & \\
\hline Реактикя & $\mathrm{pH}$ & 7,6 & 6,8 & 7,2 & 7,0 & 7,1 & 7,8 & $I$ \\
\hline Цвет & $\mathrm{mrPt} / \mathrm{um}^{3}$ & серып̆ & серыц̆ & 60 & 40 & 40 & 25 & I \\
\hline Зanax & $\begin{array}{l}\text { В холодном } \\
\text { вияе }\end{array}$ & $\begin{array}{c}\text { IV } \\
\text { гишлостиый }\end{array}$ & \begin{tabular}{|c|} 
IV \\
гнклостный
\end{tabular} & П спеч. & II R & II R & IR & 1 \\
\hline $\mathrm{BZT}_{5}$ & $\mathrm{mrO}_{2} / \mathrm{mm}^{3}$ & 365 & 342 & 19 & 6,3 & 5,8 & 1,3 & 1 \\
\hline ChZTMN & $\mathrm{mrO}_{2} / \mathrm{Am}^{3}$ & 130 & 88 & 13 & 7,1 & 8,3 & 7,1 & I \\
\hline Общая совмес. & $\mathrm{mr} / \mathrm{mm}^{3}$ & 714 & 464 & 52 & 30 & 38 & 32 & 1 \\
\hline (Rosror ogólny)" & $\mathrm{mrP} / \mathrm{mm}^{3}$ & 140 & 63 & 8 & 6 & 11 & 4 & I \\
\hline АММиаभғый азот & $\mathrm{mrN}_{\mathrm{NH} /} / \mathrm{Am}^{3}$ & 100 & 61,2 & 1,86 & 0,40 & 0,34 & 0,32 & $\bar{T}$ \\
\hline НитритҢщй азот & $\mathrm{mrN}_{\mathrm{NO} 2} / \mathrm{Am}^{3}$ & 0,007 & 0,002 & 0,398 & 0,009 & 0,003 & 0,002 & I \\
\hline Нитратьњц̆ азот & $\mathrm{mrN}_{\mathrm{NO} 3} / \mathrm{Am}^{3}$ & 0,15 & 0,27 & 21,2 & 15,3 & 0,06 & 0,05 & ] \\
\hline Обпџй азот & $\mathrm{mrN} / \mathrm{am}^{3}$ & 135,2 & 69,3 & 24,7 & 16,9 & 1,84 & 1,59 & 1 \\
\hline Фжффаты & $\mathrm{mrPO}_{4} / \mathrm{Am}^{3}$ & 31,2 & 21,9 & 12,6 & 3,82 & 1,21 & 0,08 & 1 \\
\hline Общй фосфор & $\mathrm{mrP} / \mathrm{mm}^{3}$ & 12,1 & 8,82 & 6,3 & 3,3 & 0,72 & 0,06 & $\mathrm{I}$ \\
\hline \multicolumn{8}{|c|}{ Нндекс коэрициента полезного дейстевия } & 1,66 \\
\hline \multicolumn{8}{|c|}{ 3ona (seprobowaści) } & 3 \\
\hline \multicolumn{8}{|c|}{ Болезнемворные бактерии } & - \\
\hline
\end{tabular}

\section{JHTEPATYPA}

1. Wissing F [1995]: WasserreinigungmitPfianzen. Verlag Eugen Ulmer GmbH u.Co. Stuttgard.

2. Kowalik P., Obraska-Pempkowiak H [1995]: Ociena naturalnych metod oczyszczzania ścieków. Materiały konferencyjne. Politechnika Świętokryska.

3. Osmolska-Mróz B \{1995\}: Lokalne systemy unieszkodliwiania ścieków. IOŚ W-wa.

4. Siiuta J., Wasiak G.[1995\}: Gruntowo-roślinne oczyszczalnie ścieków. Ekoinżynieria Nr 4.

5. Kowalik P., Obarska-Pempkowiak H [1994]: Zasady pracy małych hydrobotaniccznych oczyszczalni ścieków. Materiały informacyjne $\mathrm{Nr} 28$, ImiUR, Falent.

6. Wyniki analiz z 1993-1998. WIOŚ. Zielona Góra.

7. Materiały udostępnione przez Paula Fiedlera.

* brak odpowiednika rosyjskiego w źródle. 